ORIGINAL ARTICLE

\title{
Municipal pleural cancer mortality in Spain
}

\section{G López-Abente, V Hernández-Barrera, M Pollán, N Aragonés, B Pérez-Gómez}

Occup Environ Med 2005;62:195-199. doi: 10.1136/oem.2004.015743

\begin{abstract}
See end of article for authors' affiliations .....................

Correspondence to: Dr G López-Abente, Area de Epidemiología Ambiental y Cáncer, Centro Nacional de Epidemiología, Instituto de Salud Carlos III, Sinesio Delgado, 6, 28029 Madrid, Spain; glabente@ isciii.es
\end{abstract}

\begin{abstract}
Background: Pleural cancer is a recognised indicator of exposure to asbestos and mesothelioma mortality. Aims: To investigate the distribution of municipal mortality due to this tumour, using the autoregressive spatial model proposed by Besag, York, and Molliè.

Methods: It was possible to compile and ascertain the posterior distribution of relative risk on the basis of a single Bayesian spatial model covering all of Spain's 8077 municipal areas. Maps were plotted depicting standardised mortality ratios, smoothed relative risk (RR) estimates, and the distribution of the posterior probability that RR $>1$.

Results: There was a higher risk of death due to pleural cancer in well defined towns and areas, many of which correspond to municipalities where asbestos using industries once existed for many years, the prime example being the municipal pattern registered for Barcelona Province. The quality of mortality data, the suitability of the model used, and the usefulness of municipal atlases for environmental surveillance are discussed.
\end{abstract}

U ntil a few years ago, geographic studies were restricted to the drawing up of thematic maps in which large areas, generally provinces in the case of Spain, were selected as the basic study unit. Yet while this representation has shown itself to be useful for describing spatial patterns in broad terms, it nevertheless proves inadequate if the aim is to conduct an indepth study into the origin of some specific disease. For this purpose, it becomes necessary to resort to a smaller geographic scale, usually health district or municipal area, which in turn entails dealing with the inherent problem that has come to be called "analysis of small areas". Recent advances in the discipline known as spatial epidemiology, especially those advances relating to methods of analysis of spatial data, ${ }^{1-3}$ have opened the way to new approaches to mortality analysis which enable these challenges to be successfully met.

In this paper, we apply these methods to the study of municipal distribution of pleural cancer mortality in Spain, an acknowledged indicator of exposure to asbestos and mesothelioma mortality. ${ }^{4}$ Most mesotheliomas are due to exposure to asbestos, with $80-85 \%$ of cases attributable to occupational exposure. Increased risk has been reported for workers employed in asbestos mines, asbestos plants, the installation and manufacture of insulating materials, the production of anti-gas masks, shipyards, railways, and other occupations involving inhalation of asbestos dust. ${ }^{5-7}$

Furthermore, there are also reports of mesothelioma development deriving from non-occupational exposure to asbestos. This problem is present in populations living in the proximity of asbestos mines and plants, and family members of workers, who come into household contact with asbestos dust deposited and brought home on work clothes..$^{8-11}$ The presence of asbestos in the structure of buildings is yet another potential risk for the appearance of mesotheliomas, due to the release of fibres in asbestos stripping and demolition tasks. ${ }^{5}$

\section{METHODS}

Individual death entries for the period 1989-98 were used to ascertain the number of pleural cancer deaths corresponding to ICD-9 rubric 163 ("Malignant neoplasm of pleura"). These data, which include information on town or city of residence, were supplied by the National Statistics Institute (Instituto Nacional de Estadística, INE) for the production of a municipal cancer mortality atlas, of which these results form part.
The municipal populations, broken down by age group ( 18 groups) and sex, were drawn from the 1991 census and 1996 voters roll. These years correspond to the midway points of the two quinquennia that comprise the study period (198993 and 1994-98), thereby rendering it easy to ascertain person-years by multiplying the populations by 5 .

Standardised mortality ratios (SMR) were calculated as the ratio between observed and expected deaths. For the calculation of expected cases, the overall Spanish mortality rates for the above two 5-year periods were applied to each town's person-years by age group, sex, and quinquennium.

The calculation of smoothed municipal relative risks (RR) for map plotting purposes was based on fitting spatial Poisson models with two random effects terms that took the following into account: (a) municipal contiguity (spatial term); and (b) municipal heterogeneity. These models come within the so-called conditional autoregressive (CAR) models for drawing up disease maps, initially proposed by Besag and colleagues ${ }^{12}$ and subsequently applied in the field of epidemiology. ${ }^{13}$ The models were fitted using Bayesian Markov chain Monte Carlo simulation methods with noninformative priors. ${ }^{14}$ Posterior distributions of relative risk were obtained using WinBugs. ${ }^{15}{ }^{16}$ The criterion of contiguity used was adjacency of municipal boundaries. The model fitted is known as the Besag, York, and Molliè (BYM) model and an explicit formulation of the same and the WinBugs code we have used can be consulted in GeoBUGS. ${ }^{16}$ Convergence of the simulations was verified using the BOA (Bayesian output analysis) $\mathrm{R}$ program library. ${ }^{17}$ Given the great number of parameters of the models, the convergence analysis was performed on a randomly selected sample of 10 towns and cities, taking strata defined by municipal size.

The results of the models were included in a geographic information system to plot maps that depicted standardised mortality ratios, smoothed RR estimates, and the distribution of the posterior probability that RR $>1$.

\section{RESULTS}

From 1989 to 1998, a total of 1647 pleural cancer related deaths were registered in Spain. Cases were registered in only 601 towns and cities. The majority of towns without cases

Abbreviations: RR, relative risk; SMR, standardised mortality ratio 


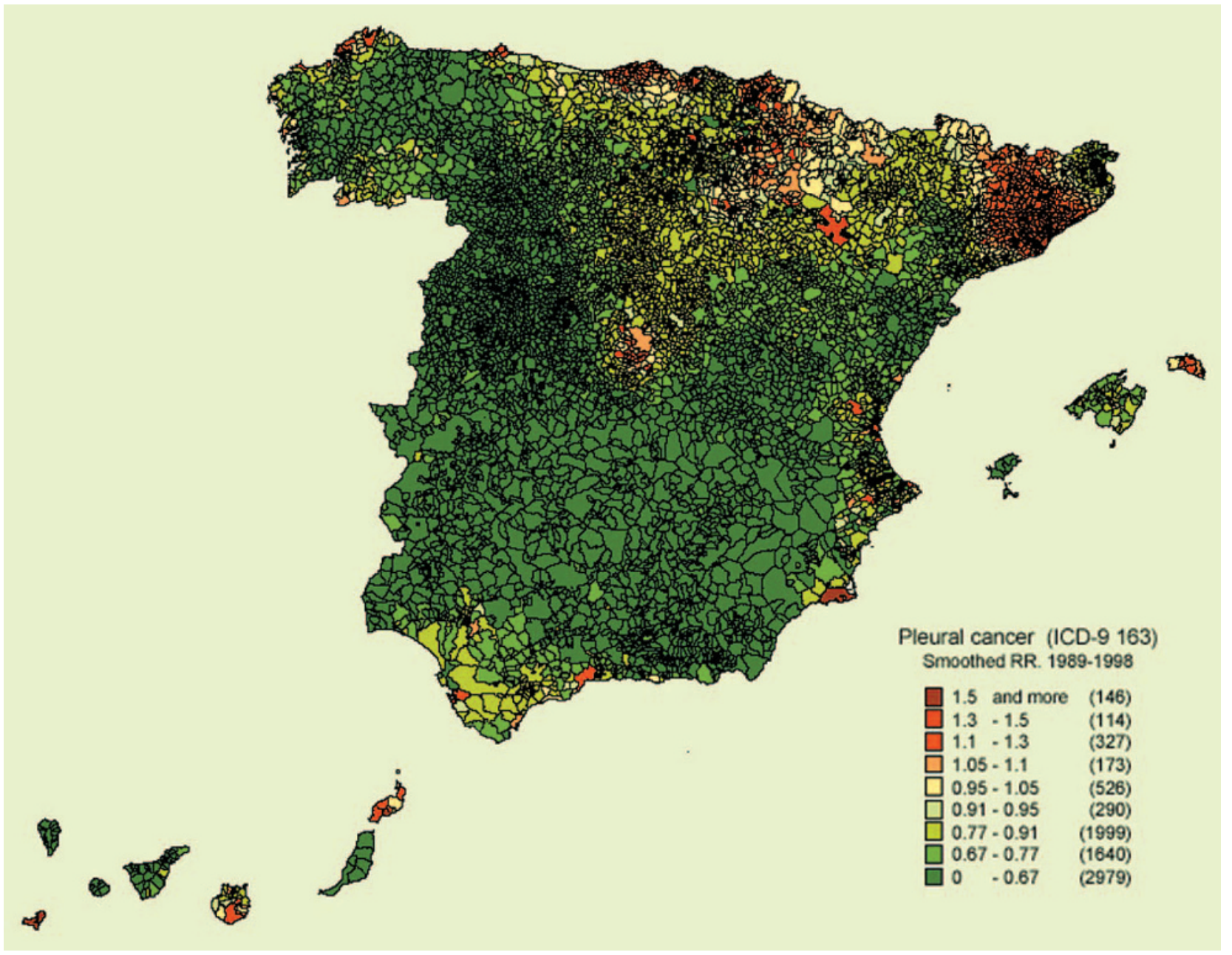

Figure 1 Distribution pattern of the smoothed relative risk (RR) for pleural cancer mortality in Spain, 1989-98.

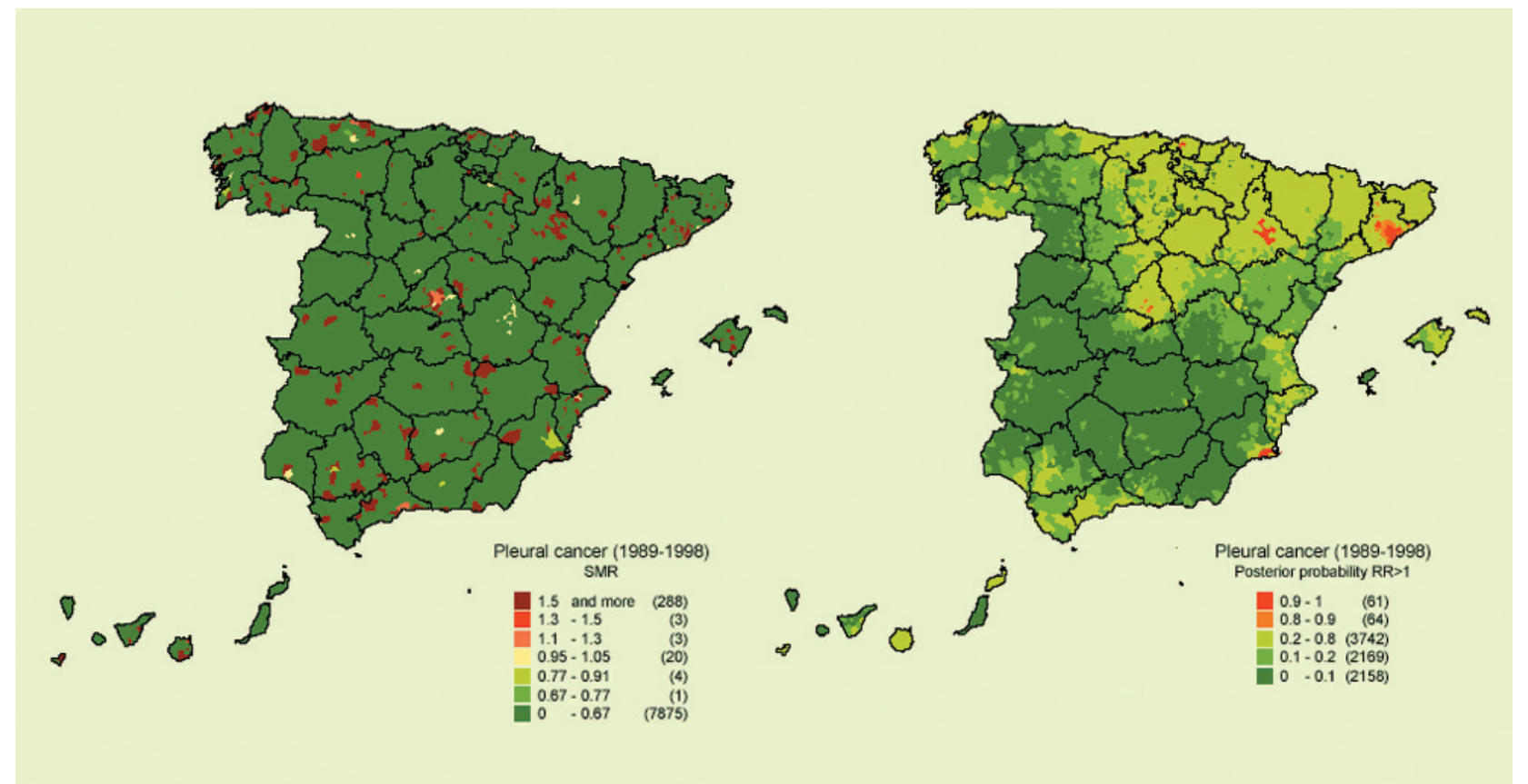

Figure 2 Distribution pattern of the standardised mortality ratio (left) and the posterior probability of RR being greater than 1 (right). Pleural cancer mortality, Spain, 1989-98. 
had fewer than 3500 inhabitants. Using these data, an acceptable computation time, and conventional computers, we were able to compile and ascertain the posterior distribution of relative risk on the basis of a single spatial model that included all of Spain's 8077 towns and cities and the 47916 adjacencies existing between them.

Convergence of the estimators was achieved before 100000 iterations. For the maps shown, a "burn-in" (iterations discarded to ensure convergence) of 300000 iterations was performed and the posterior distribution was derived with 5000 .

Figure 1 depicts the distribution pattern of the smoothed relative risk (RR), and fig 2 depicts the SMR and the posterior probability of the estimated RR being greater than 1 .

The SMR map (fig 2) shows the polarisation of the distribution towards its extremes (towns with and without cases), with no specific pattern being clearly discernable. The "noise" present in this map, deriving from the instability of the indicator, is filtered by the smoothing procedure, the result of which is shown in fig 1 .

A peculiarity of this smoothed map is that, with a certain degree of accuracy, it "flags" those towns and cities in which some form of exposure to asbestos has occurred. Hence, places such as El Ferrol, Cartagena, Cadiz, Avilés, and Santander, in which shipyards or some other type of asbestos using industry existed for many years, are highlighted.

Barcelona Province displays a remarkable pattern of excess mortality. It is home to the localities with highest risk, particularly those situated in the Vallés District, with Cerdanyola being the town to register the highest RR in Spain. This pattern is found in no other province or region. Possibly, it is the fibre-cement industry that accounts for this increased risk in the Province of Barcelona ${ }^{18}$ as well as the pattern observed in the south of the Madrid Region (Getafe).

Table 1 shows information on observed and expected deaths in the most representative towns situated in each area in which excess mortality was detected. The map that indicates the distribution of these municipalities, along with their respective probabilities of having excess mortality, is shown in fig 2.

\section{DISCUSSION}

The results of this study reveal a higher risk of death due to pleural cancer in well defined towns and areas, many of which correspond to municipalities that were once the site of industries where asbestos was used for many years.

The carcinogenic properties of asbestos have been known since the 1930s. ${ }^{19}$ Amphiboles in general, and crocidolite in particular, exert the greatest carcinogenic power, something that is apparently attributable to the diameter and structure of the fibres. A low level of exposure is suffice to cause a tumour, with a minimum latency period of 10 years. ${ }^{56}$

Regulation and prohibition of asbestos have been implemented in many developed countries, with Iceland being the first country to ban this substance in 1983. In 1999, the European Union called for the prohibition of all types of asbestos, with express reference to chrysotile, a ban that is to be extended to all EU members by the appointed deadline of 1 January 2005 (Commission Directive 1999/77/EC of 26 July 1999, EU 1999). In Spain, the use of crocidolite was prohibited in 1984: the use and sale of chrysotile was restricted in 1989 and subsequently banned in 2001, following formal adoption of the provisions of the European directive.

Although pleural cancer is extremely infrequent in Spain, during the last 10 years for which mortality data are available, the trend in pleural cancer rates nevertheless indicates an increase in men, rising from 0.40 per 100000 population in 1980 to 0.78 in 2001 (in absolute terms, there were 61 pleural cancer deaths in men in 1980 versus 173 in 2001). In women, however, no such rising trend is displayed by the rates ( 0.23 in 1980 and 0.22 in 2001).

With respect to the data used, a limitation to be borne in mind is that the accuracy of certification of pleural tumours in Spain is less than that for other tumour sites. ${ }^{20}{ }^{21}$ Based on earlier evaluations, we know that part of the diagnoses of mesotheliomas or pleural cancers might possibly be coded as malignant neoplasm of unspecified site. ${ }^{22}$ Furthermore, an assessment made in Italy $^{23}$ reported $75 \%$ concordance between anatomopathological diagnosis and death certificate. In the case of pleural tumours, problems in certification would mean that risk was underestimated in some towns and cities, though there is no reason to think that coding procedures might differ between the respective mortality registries entrusted with this task.

In general terms, the regression model seems to function correctly, yielding a pattern that is plausible in the light of earlier provincial maps. In the Provincial Atlas $^{24}$ the areas

Table 1 Towns and cities with pleural cancer excess mortality, selected; Spain, 1989-98

\begin{tabular}{|c|c|c|c|c|c|c|c|c|}
\hline City or town & Province & Observed & Expected & SMR & $p$ value & Smoothed RR & $\begin{array}{l}\text { RR credibility } \\
\text { interval } \\
2.5 \%-97.5 \%\end{array}$ & $p(R R>1)$ \\
\hline Badalona & Barcelona & 20 & 7.58 & 2.64 & 0.0000 & 2.48 & $1.60-3.55$ & 1 \\
\hline Barcelona & Barcelona & 165 & 79.82 & 2.07 & 0.0000 & 2.06 & $1.77-2.38$ & 1 \\
\hline Hospitalet De Llobregat & Barcelona & 24 & 10.65 & 2.25 & 0.0001 & 2.14 & $1.44-3.03$ & 1 \\
\hline Manresa & Barcelona & 8 & 3.26 & 2.45 & 0.0065 & 1.90 & $1.05-3.16$ & 0.98 \\
\hline Montcada I Reixac & Barcelona & 5 & 0.98 & 5.10 & 0.0005 & 3.12 & $1.63-5.46$ & 1 \\
\hline Ripollet & Barcelona & 6 & 0.88 & 6.83 & 0.0000 & 4.51 & $2.09-8.24$ & 1 \\
\hline Sabadell & Barcelona & 19 & 7.57 & 2.51 & 0.0001 & 2.51 & $1.63-3.60$ & 1 \\
\hline Cerdanyola Del Valles & Barcelona & 15 & 1.49 & 10.05 & 0.0000 & 5.80 & $3.24-9.57$ & 1 \\
\hline Terrassa & Barcelona & 15 & 6.55 & 2.29 & 0.0013 & 2.13 & $1.33-3.16$ & 1 \\
\hline Miranda De Ebro & Burgos & 6 & 1.62 & 3.72 & 0.0014 & 1.39 & $0.64-2.64$ & 0.77 \\
\hline Cadiz & Cádiz & 19 & 5.24 & 3.63 & 0.0000 & 3.22 & $1.91-4.85$ & 1 \\
\hline Ferrol & La Coruña & 9 & 3.86 & 2.33 & 0.0064 & 2.01 & $0.92-3.51$ & 0.96 \\
\hline Getafe & Madrid & 12 & 4.19 & 2.86 & 0.0004 & 1.89 & $1.08-3.07$ & 1 \\
\hline Mostoles & Madrid & 9 & 4.11 & 2.19 & 0.0097 & 1.58 & $0.84-2.61$ & 0.93 \\
\hline Pozuelo De Alarcon & Madrid & 5 & 1.52 & 3.30 & 0.0047 & 1.70 & $0.76-3.27$ & 0.9 \\
\hline Cartagena & Murcia & 20 & 6.27 & 3.19 & 0.0000 & 2.06 & $1.20-3.20$ & 1 \\
\hline Pamplona & Navarra & 24 & 7.56 & 3.18 & 0.0000 & 2.41 & $1.53-3.51$ & 1 \\
\hline Santander & Santander & 15 & 8.16 & 1.84 & 0.0098 & 1.75 & $1.02-2.70$ & 0.98 \\
\hline Barakaldo & Vizcaya & 10 & 4.46 & 2.24 & 0.0063 & 1.63 & $0.90-2.66$ & 0.94 \\
\hline Zaragoza & Zaragoza & 45 & 25.89 & 1.74 & 0.0002 & 1.48 & $1.08-1.93$ & 0.99 \\
\hline
\end{tabular}

Municipalities having excess mortality and registering 5 or more observed cases were selected for this table. Credibility interval: Bayesian equivalent to confidence interval. 
registering highest mortality were Barcelona, Las Palmas, Guipúzcoa, Vizcaya, and Zaragoza among men, and Barcelona, Huesca, Navarre, and Melilla for women. However, in many other cases where very few towns in the province as a whole were affected, as is the case of Murcia, La Coruña, Cádiz, Santander, or even Madrid, the pattern was hidden by the averaging entailed in such large areas being regarded as provinces. Excess pleural cancer mortality in the Province of Barcelona has already been highlighted. ${ }^{18}$

Observation of unsmoothed and smoothed maps raises the question of the usefulness of these techniques in the case of tumours as rare as pleural cancer, in which the majority of towns and cities have no cases. What the (unsmoothed) SMR map appears to show are towns with and without cases, so that the larger towns and cities thus have a higher likelihood of being represented. The smoothed RR map "filters" this situation, by eliminating part of the random variability, showing the patterns, and highlighting those areas in which risk is concentrated. Furthermore, the information generated in the smoothed map must be interpreted globally, without recourse to estimators of isolated towns and cities (for example, a place where a case has never occurred cannot be accorded high risk status). Towns not registering any excess risk may nevertheless be made to appear as doing so by the smoothing process, simply because their neighbours have excess risk. However, this phenomenon, which could be manifesting itself in some towns and cities in the Province of Barcelona, appears to be insignificant in other areas, such as the City of Cádiz, Zaragoza, El Ferrol, or Cartagena, where neighbouring towns hardly seem to be contaminated by the spatial averaging procedure. To a certain extent, the smoothing procedure seems to respect the singularity of highest risk towns. The possibility of false positives being taken into account is reduced by the map that shows the probability of there being excess cases.

In parallel with this, there could be a problem of false negatives-that is, small towns that register risk may disappear as a result of the smoothing procedure. This could be the situation of areas of Castile or Extremadura (SMR map). An aspect that warrants more study is the adaptation of these models to situations such as these, where there are large numbers of towns without pleural cancer deaths, or towns with excess cases surrounded by towns and cities without any cases. Other alternative strategies of analysis to be considered in such circumstances could be the use of models with a mixture of distributions that take discontinuities (jumps in the pattern) into account or "zero inflated Poisson" (ZIP) models. ${ }^{25-27}$

Despite the possible limitations attaching to such techniques due to their recent implementation in the field of epidemiology, the results are clearly able to pinpoint areas where there were industrial facilities in which asbestos was used.

What the mortality analysis is only now highlighting are the consequences of using asbestos in this country for many years. It has been estimated that the number of workers exposed to asbestos in 1991 was $60488^{28}$ in Spain and 1.2 million $(0.86 \%$ of the economically active population) in the European Union, $50 \%$ as construction workers. ${ }^{29}$ As a result, pleural (and peritoneal) mesothelioma will continue to constitute a public health problem for decades to come. ${ }^{3031}$ The manufacture of asbestos products is not prohibited in many developing countries, and in producing countries such as Canada, the export of chrysotile is permitted. ${ }^{11}$

Apart from its association with mesotheliomas, asbestos is also a recognised causal agent of lung cancer. The joint effect of asbestos and tobacco produce a multiplicative risk of lung cancer. However, geographic lung cancer mortality patterns in Spain are very different to those for pleural cancer. ${ }^{24}$ Some studies have reported a modest increase in the risk of laryngeal cancer and gastrointestinal, bile duct, and haema- topoietic tumours, though there is insufficient evidence to conclude that asbestos fibres are the cause of tumours other than mesothelioma and lung cancer. ${ }^{5}$

With respect to the possible presence of other risk factors in the geographic patterns detected, the implication of Simian virus 40 (SV40) per se in pleural cancer mortality ${ }^{32}$ would not seem probable. Nevertheless, more in-depth study is called for, due to its possible relation with other types of tumours. ${ }^{33}$

Although the case of pleural tumours and mesotheliomas is very singular, municipal maps may well prove to be a highly useful element in environmental surveillance. Their principal limitation lies in the long latency periods in the aetiology of the cancer, together with the progressive increase in survival that is being seen in some types of neoplasias. Hence, the pattern detected is the consequence of exposures that took place a number of decades ago. This lag could be shortened if these techniques were applied to cancer incidence data. If surveillance mechanisms, capable of expediting detection of the presence of environmental exposures which posed a possible health risk to workers and the general population, could be established, this would be of vital importance: it would mean that researchers were no longer be confined to spotlighting the consequences of occupational and environmental catastrophes, as is now the case with past exposure to asbestos.

\section{ACKNOWLEDGEMENTS}

This study was financed by Grant No. EPY-1176/02 from the Carlos III Institute of Health (ISCIII) and RCESP C03/09 (Spanish Network for Cooperative Research in Epidemiology and Public Health).

\section{Authors' affiliations}

G López-Abente, V Hernández-Barrera, M Pollán, N Aragonés, B Pérez-Gómez, Environmental and Cancer Epidemiology Unit, National Centre for Epidemiology, Carlos III Institute of Health, Madrid, Spain

\section{REFERENCES}

1 Cressie N. Statistics for spatial data. New York: Wiley, 1991.

2 Lawson A, Biggeri A, Böhning D, et al. Disease mapping and risk assessment for public health. Chichester: Wiley, 1999.

3 Elliot P, Wakefield C, Best NG, et al. Spatial epidemiology. New York: Oxford, 2000.

4 Micheli A, Capocaccia R, Martinez C, et al. Cancer control in Europe: a proposed set of European cancer health indicators. Eur J Public Health 2003; 13(suppl 3): 116-18.

5 International Agency for Research on Cancer. Overall evaluations of carcinogenicity: an updating of IARC monographs, volumes 1 to 42, Supplement No. 7. Lyon: IARC, 1987.

6 World Health Organisation. International programme on chemical safety. Environmental health criteria 203, Chrysotile asbestos. Geneva: WHO, 1998.

7 Agudo A, González CA, Bleda MJ, et al. Occupation and risk of malignant pleural mesothelioma: a case-control study in Spain. Am J Ind Med, 2000;37:159-68.

8 Magnani C, Terracini B, Ivaldi C, et al. Pleural malignant mesothelioma and non-occupational exposure to asbestos in Casale Monferrato, Italy. Occup Environ Med 1995;52:362-7.

9 Magnani C, Agudo A, Gonzalez CA, et al. Multicentric study on malignant pleural mesothelioma and non-occupational exposure to asbestos. $\mathrm{Br} J$ Cancer 2000;83:104-11.

10 Browne K, Goffe T. Mesothelioma due to domestic exposure to asbestos. BMJ (Clin Res Ed) 1984;289:110-11.

11 Agudo A. Mesotelioma pleural y exposición ambiental al amianto. Tesis doctoral. Barcelona: Universitat Autónoma de Barcelona, 2003.

12 Besag J, York J, Molliè A. Bayesian image restoration, with applications in spatial statistics. Annals of the Institute of Statistics and Mathematics 1991;43:1-59.

13 Clayton DG, Bernardinelli L, Montomoli C. Spatial correlation in ecological analysis. Int J Epidemiol 1993;22: 1193-202.

14 Gilks WR, Richardson S, Spiegelhalter DJ. Markov chain Monte Carlo in practice. London: Chapman Hall, 1996.

15 Spiegelhalter D, Thomas D, Best N, et al. BUGS: Bayesian inference using Gibbs sampling. Version 0.50. Cambridge: MRC Biostatistics Unit, 1996.

16 Thomas D, Best N, Lunn D, et al. GeoBUGS User Manual. Version 1.2, September 2004. London: Imperial College and MRC, 2004.

17 Smith BJ. Bayesian Output Analysis Program (BOA), Version 0.99.1 for S-PLUS and R. http://www.public-health.uiowa.edu/BOA, 2001. 
18 González CA, Agudo A, Ruano I, et al. Mortalidad por mesotelioma pleural en la provincia de Barcelona. Med Clin (Barc) 1993;101:565-9.

19 Craighead JE, Mossman BT. The pathogenesis of asbestos-associated diseases. N Engl J Med 1982;306:1446-55.

20 Cáffaro M, Garau I, Cabeza E, et al. Validez de los certificados de defunción por cáncer en Mallorca. Gac Sanit 1995;9:166-73.

21 Cirera L, Navarro C. Validez de la certificación de la muerte por cáncer en la Comunidad de Murcia. Oncología 2002;25:264-72.

22 Kelson M, Farebrother M. The effect of inaccuracies in death certification and coding practices in the European Economic Community (EEC) on international cancer mortality statistics. Int J Epidemiol 1987;16:411-14.

23 Bruno C, Comba P, Maiozzi P, et al. Accuracy of death certification of pleural mesothelioma in Italy. Eur J Epidemiol 1996;12:421-3.

24 López-Abente G, Pollán M, Escolar A, et al. Atlas de mortalidad por cáncer y otras causas en España, 1978-1992. Madrid: Instituto de Salud Carlos III, 2001

25 Lawson AB, Clark A. Spatial mixture relative risk models applied to disease mapping. Stat Med 2002;21:359-70.

26 Lambert D. Zero-inflated Poisson regression, with an application to defects in manufacturing. Technometrics 1992;34:1-14.
27 Hall DB. Zero-inflated Poisson and binomial regression with random effects: a case study. Biometrics 2000;56:1030-9.

28 INHST (National Institute for Hygiene and Safety in the Workplace). Study of incidence and evaluation of a working population exposed to asbestos in Spanish industry. Madrid: Instituto Nacional de Higiene y Seguridad en el Trabajo, 1992.

29 Kauppinen T, Toikkanen J, Pedersen D, et al. Occupational exposure to carcinogens in the European Union in 1990-1993. CAREX. International information system on Occupational Exposure to Carcinogens. Helsinki: Finnish Institute of Occupational Health, 1998.

30 Peto J, Decarli A, La Vecchia C, et al. The European mesothelioma epidemic. Br J Cancer 1999;79:666-72.

31 La Vecchia C, Decarli A, Peto J, et al. An age, period and cohort analysis of pleural cancer mortality in Europe. Eur J Cancer Prev 2000;9:179-84.

32 Carbone M, Rizzo P, Pass H. Simian virus 40: the link with human malignant mesothelioma is well established. Anticancer Res 2000;20:875-7.

33 Vilchez RA, Butel JS. SV40 in human brain cancers and non-Hodgkin's lymphoma. Oncogene 2003;22:5164-72. 